\title{
An evaluation of the enhanced oil recovery potential of the xanthan gum and aquagel in a heavy oil reservoir in Trinidad
}

\author{
Tina Coolman ${ }^{1} \cdot$ David Alexander $^{1} \cdot$ Rean Maharaj $^{1} \cdot$ Mohammad Soroush $^{1}$
}

Received: 15 September 2019 / Accepted: 25 March 2020 / Published online: 16 April 2020

(c) The Author(s) 2020

\begin{abstract}
The economy of Trinidad and Tobago which mainly relies on its energy sector is facing significant challenges due to declining crude oil production in a low commodity price environment. The need for enhanced oil recovery (EOR) methods to meet the current and future energy demands is urgent. Studies on the use of polymer flooding in Trinidad and Tobago are limited, especially in terms of necessary data concerning the characterization of the adsorption of polymer flooding chemicals such as xanthan gum and aquagel polymers on different soil types in Trinidad and the viscosity characteristics of the polymer flooding solutions which affect the key attributes of displacement and sweep efficiency that are needed to predict recovery efficiency and the potential use of these flooding agents in a particular well. Adsorption and viscosity experiments were conducted using xanthan gum and aquagel on three different soil types, namely sand, Valencia clay (high iron) and Longdenville clay (low iron). Xanthan gum exhibited the lowest adsorption capacity for Valencia clay but absorbed most on sand at concentrations above $1000 \mathrm{ppm}$ and Longdenville clay below $1000 \mathrm{ppm}$. At concentrations below $250 \mathrm{ppm}$, all three soil-type absorbent materials exhibited similar adsorption capacities. Aquagel was more significantly absorbed on the three soil types compared to xanthan gum. The lowest adsorption capacity was observed for Valencia clay at concentration levels above $500 \mathrm{ppm}$; however, the clay had the highest adsorption capacity below this level. Sand had the highest adsorption capacity for aquagel at concentrations above $500 \mathrm{ppm}$ while Longdenville clay was the lowest absorbent above $500 \mathrm{ppm}$. Generally, all three soil types had a similar adsorption capacity for xanthan gum at a concentration level of $250 \mathrm{ppm}$ and for aquagel at a concentration level of $500 \mathrm{ppm}$. The results offered conclusive evidence demonstrating the importance that the pore structure characteristics of soil that may be present in oil wells on its adsorption characteristics and efficiency. Xanthan gum polymer concentration of $2000 \mathrm{ppm}, 1000 \mathrm{ppm}$ and $250 \mathrm{ppm}$ showed viscosities of $125 \mathrm{cp}, 63 \mathrm{cp}$ and $42 \mathrm{cp}$, respectively. Aquagel polymer concentrations of $2000 \mathrm{ppm}, 1000 \mathrm{ppm}$ and $250 \mathrm{ppm}$ showed viscosities of $63 \mathrm{cp}, 42 \mathrm{cp}$ and $21 \mathrm{cp}$, respectively. Aquagel polymer solutions were found to generally have lower viscosities than the xanthan gum polymer solutions at the same concentration. Adsorption and viscosity data for the xanthan gum and aquagel polymers were incorporated within CMG numerical simulation models to determine the technical feasibility of implementing a polymer flood in the selected EOR 44 located in the Oropouche field in the southwest peninsula of the island of Trinidad. Overall, aquagel polymer flood resulted in a higher oil recovery of 0.06 STB compared to the xanthan gum polymer flood, so the better EOR method would be aquagel polymer flood. Additionally, both cases of polymer flooding resulted in higher levels of oil recovery compared to $\mathrm{CO}_{2}$ injection and waterflooding and therefore polymer flooding will have greater impact on the EOR 44 well oil recovery.
\end{abstract}

Keywords Polymer flood $\cdot$ Xanthan gum $\cdot$ Aquagel $\cdot$ EOR $\cdot$ Waterflood

\section{Introduction}

The economy of Trinidad and Tobago relies heavily on its energy sector accounting for over $30 \%$ of its GDP. An

Tina Coolman

tinacoolman@live.com

1 Energy Systems Engineering, University of Trinidad and Tobago, Couva, Trinidad and Tobago analysis of economic growth between 2000 and 2007 indicates that it averaged over $8 \%$ annually; however, since then, the GDP of the economy has slowed as it has contracted during 2009-2012, recorded a slight recovery in 2013 but 
contracting again in 2014-2017. These fluctuating trends can be directly correlated with the fluctuating oil and natural gas commodity prices during the same period. Today, the country is still grappling with the challenges of natural gas production shortages, declining crude oil production and a low commodity price environment. Trinidad and Tobago produces approximately nine times more natural gas than crude oil on an energy equivalent basis with the proceeds of natural gas production accounting for approximately twothirds of energy of the revenue obtained from the energy sector.

According to Trading Economics (2019), Crude Oil Production in Trinidad and Tobago has shown a marked decline in recent years and averaged 107.97 BBL/D/1 K from 1994 until 2019. Maximum crude oil production occurred in March of 2005, and a record low of 51 BBL/D/1 K occurred in March of 2019. Figure 1 shows the crude oil production in Trinidad and Tobago by year from 1994 to 2019.

The decreased crude oil production that coupled with a decrease in the number of new discoveries of oil and gas reserves in Trinidad has prompted the need for the utilization of methods of enhanced oil recovery (EOR) to meet the current and future energy demands and to mitigate the negative effects of the current shortfalls on the national economy. Thus far, Trinidad and Tobago has produced over $320 \mathrm{MMb}-$ bls of oil via conventional secondary and EOR processes, but today few have been proven to be economically feasible and include alternating steam process (WASP), steamflood and waterflood (Ministry of Energy and Energy Industries 2019).

In Trinidad, the technique of waterflood has resulted in approximately $125 \mathrm{MMbbls}$ of oil being lifted (Ministry of Energy and Energy Industries 2019). However, despite being one of the most common improved oil recovery (IOR) methods, its utilization has diminished due to uneconomically high water cuts, inadequate water supply required for injection, mechanical and operational problems and viscous fingering (Sinanan et al. 2016). On the other hand, polymer flooding and polymer injection have proven to be one of the most important chemical EOR methods used in sandstone reservoirs. It increases the viscosity of water when added which allows for greater improved sweep efficiency and a consequential degree of enhanced oil recovery. Polymer flooding can also mitigate the challenge of the existence of high-permeability channels or a thief zone that may be encountered in a reservoir which allows fluid flow to bypass portions of the reservoir. When cross-linked polymers are injected into a reservoir, they can reduce or fully block water flow through the porous medium (Van der Hoek et al. 2001).

Two polymer projects were implemented in Trinidad in 1968 and 1974 which aimed at improving the sweep efficiency of existing waterflood by increasing the viscosity of the injected fluid. An increase in oil production in several wells was reported; however, both projects were eventually abandoned due to mechanical failures, formation plugging and source water problems (Sinanan et al. 2016). One of the negative attributes of this method is the adsorption of the polymer on the aggregate surfaces which reduces its potency as a suitable EOR method. Commonly used watersoluble polymers are generally categorized into two categories: synthetic and biopolymer. Xanthan gum is a non-ionic biopolymer, and along with aquagel it has been used in the oil exploration industry as polymer flooding agents and drilling mud (Speight 2013; Firozjaii and Saghafi 2019).

The purpose of this study is to investigate the effect of xanthan gum and aquagel polymer treatments on oil recovery factor in a typical well in Trinidad. The well investigated in this project is the EOR 44 located in the Oropouche field in the southwest peninsula of the island of Trinidad (Fig. 2). The reservoirs are deepwater sands deposited on the continental slope. Shale outs and faults confine the reservoirs in the AO-8 fault block as illustrated in Fig. 3. In the northern and southern portions of the block, there are water legs.
Fig. 1 Crude oil production in Trinidad and Tobago by year from 1994 to 2019 (Source Oil Production vs. Years by Trading Economics)

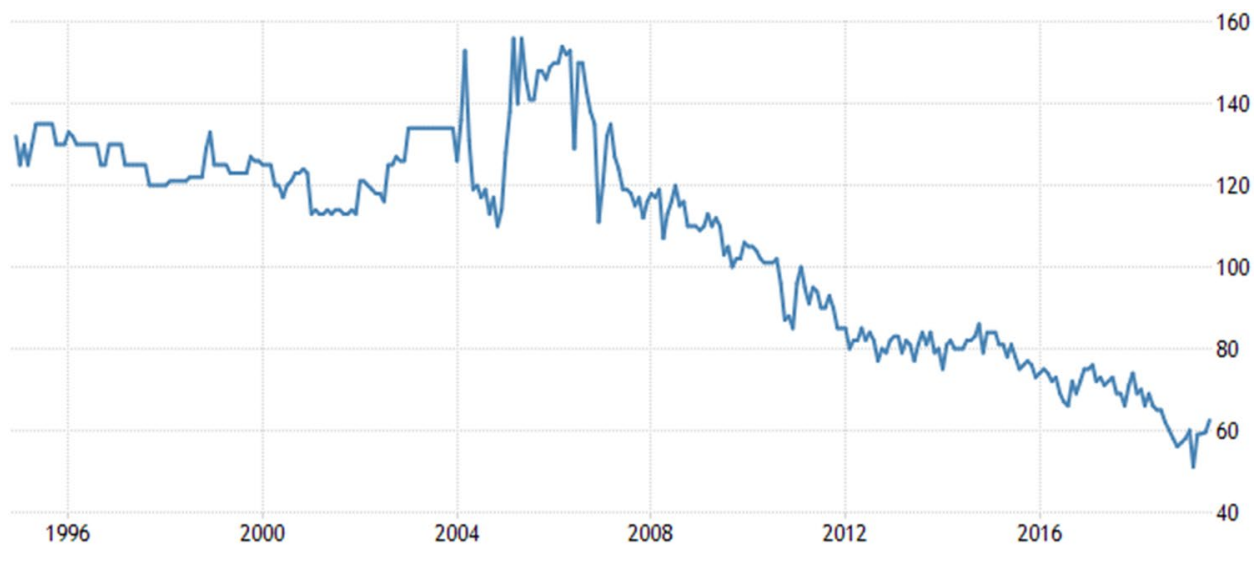

SOURCE: TRADINGECONOMCS.COM | U.S. ENERGY INFORMATION ADMINISTRATION 
Fig. 2 Location of EOR 44 in Trinidad (Mohammad-Singh and Singhal 2004)
Fig. 3 Structure contour map AO-8 sands EOR 44 (Mohammad-Singh and Singhal 2004)

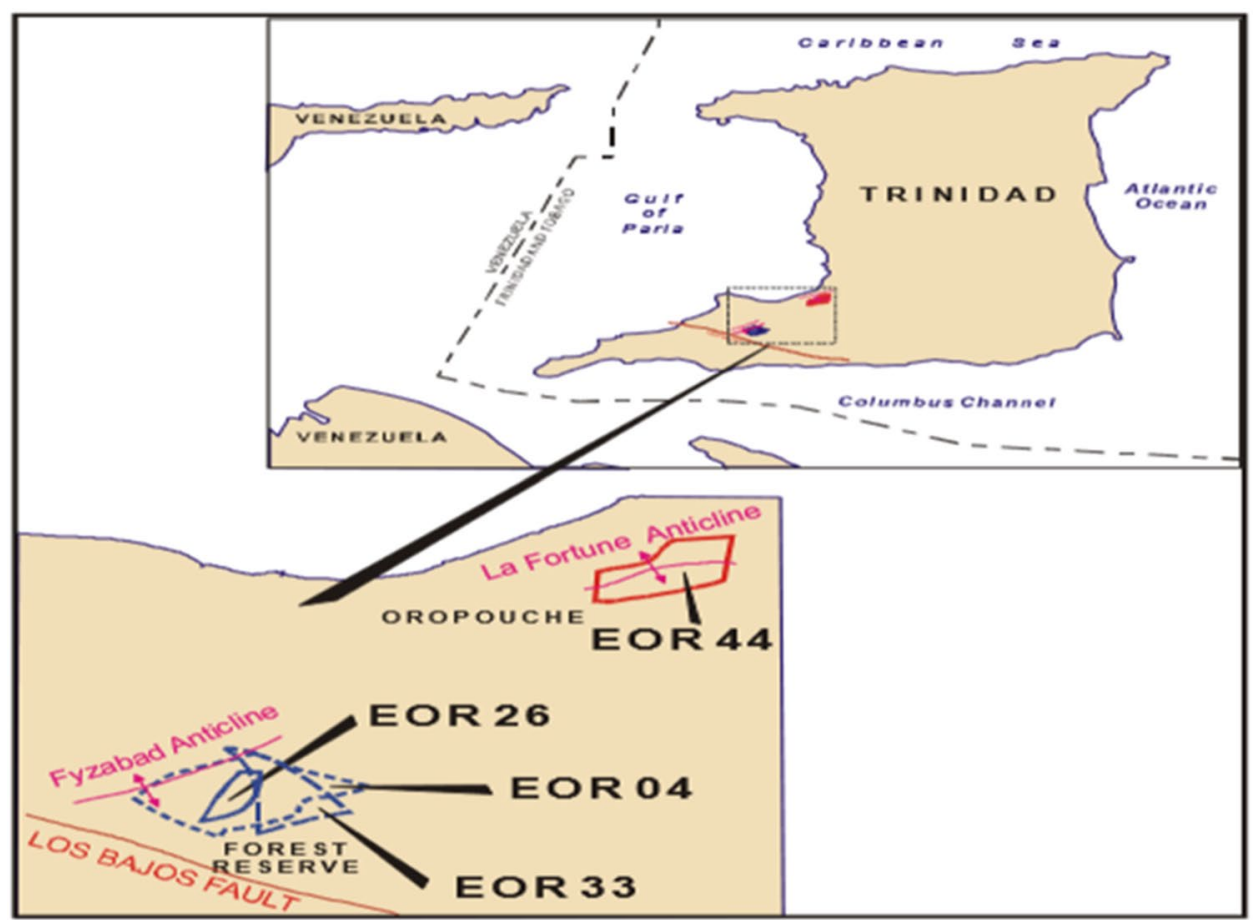

The EOR 44 project was selected to evaluate for the implementation of a polymer flood because it met the general screening criteria for this type of EOR. The EOR 44 reservoir's data are shown in Table 1, and the screening parameters are shown in Fig. 4.
Although preliminary simulation data were presented on the EOR 44 project by Mohammad-Singh and Singhal (2004), the procedure lacked input adsorption and viscosity data. Since improving the aspects of displacement efficiency and sweep efficiency improves the overall recovery 
Table 1 Reservoir data for EOR 44 well, Oropouche (MohammadSingh and Singhal 2004)

\begin{tabular}{ll}
\hline Rock properties & EOR 44 well \\
\hline Area (acs) & 175 \\
Pay zone & AO-8 \\
Depth (ft) & 2160 \\
Thickness (ft) & 35 \\
Porosity (\%) & 30 \\
Permeability (mD) & 2 to 36 \\
Oil saturation (\%) & 70 \\
Temperature ( ${ }^{\circ}$ F) & 120 \\
Transmissibility (mD-ft/cp) & 111 \\
Fluid properties & \\
Initial conditions & \\
Reservoir pressure (psi) & 1584 \\
Solution gas oil ratio (scf/bbl) & 260 \\
Oil formation volume factor $(\mathrm{bbl} / \mathrm{bbl})$ & 1.13 \\
Oil gravity ( ${ }^{\circ}$ API) & 29 \\
Oil viscosity (cp) & 5 \\
At CO $_{2}$ flood start & \\
Reservoir pressure (psi) & 375 \\
Solution gas oil ratio (scf/bbl) & 50 \\
Oil formation volume factor (bbl/bbl) & 1.04 \\
Oil viscosity (cp) & 6 \\
\hline
\end{tabular}

efficiency of a particular well, it is critical to investigate the relationship between the displacement efficiency and sweep efficiency methods on viscosity and adsorption characteristics. Adsorption and viscosity experiments were conducted using a range of polymer concentrations for both polymers incorporated in different soil types, and the results of these experiments were incorporated within numerical simulation models to determine the technical feasibility of implementing a polymer flood. The results of the adsorption and viscosity experiments were used to tweak the simulator to ensure accurate and relevant results for the field model. A review of the literature has revealed limited information and research on the adsorption and viscosity characteristics of xanthan gum and aquagel polymers and their behavior with different soil types in Trinidad and Tobago. These results of this study will therefore satisfy this information gap, and the data obtained from absorbance and viscosity characteristics of xanthan gum and aquagel polymers with different soil types in Trinidad and Tobago will render the information produced by the CMG software more accurate and realistic and present a better evaluation of the use of polymer flooding for the EOR 44 well.

The influence of a polymer on the EOR process increases the sweep efficiency. We use Eq. 1 to calculate the volumetric sweep efficiency, $E_{v}$ :

$$
E_{V}=\frac{\text { The volume of oil contacted by the displacing agent }}{\text { The volume of oil originally in place }}
$$

Equation 1: Volumetric Sweep Efficiency

Highly viscous oil will cause the water that is injected to be fingered through it and bypass it. Polymer injection generally improves the sweep efficiency by decreasing the mobility $(M)$ between the oil and water; the ideal situation should be when $M \leq 1$. The mobility, $M$, can be calculated by Eq. 2. Mobility stated by Willhite (1986) is the ratio between the effective permeability of a fluid and its viscosity. It is a relative measure of how easy a fluid moves through porous media.

$M=\frac{\text { Displacing Fluid }}{\text { Displaced Fluid }}$

Equation 1: Mobility, Willhite. (1986)

$M<1$ is the displacing fluid that moves slower than the displaced fluid which is good; $M>1$ is the displacing fluid that moves faster than the displaced fluid which is not good.

Another factor considered in a polymer flood method is the displacement efficiency. The recovery efficiency as mentioned by Willhite (1986) is lower than the displacement efficiency because not all of the oil is contacted by the displacing agent. Equation 3 can be used to calculate the displacement efficiency of oil, $E_{D}$, in which $E_{D}$ is bounded between 0 and 1. $E_{D}$ is affected by initial conditions, displacing agent, amount of the displacing agent, fluid, rock and fluid-rock properties.

$$
E_{D}=\frac{\text { Amount of oil displaced }}{\text { Amount of oil contacted by the displacing agent }}
$$

Equation 2: Displacement Efficiency of Oil, Willhite (1986)

Previous studies outside of Trinidad where polymer flooding was utilized were studied. Fondevila Sancet et al. (2018)) evaluated the effects of the combination of a biopolymer, xanthan gum and a synthetic polyacrylamide. They discovered that both polymers had shortcomings, more particularly the polyacrylamide is very susceptible to a saline environment and mechanical degradation and xanthan gum is degraded by bacteria. Various tests were carried out which included DSC, DTA, TGA, FTIR spectroscopic studies, HNMR and SEM. From these tests, it proved that by mechanical mixing it showed desirable properties of mobility control (viscosifying agent) if polymers are to be mixed together and used in a polymer flood. A study by Leonhardt et al. (2014) found that Schizophyllan is an environmentally friendly alternate synthetic polymer which is viscosity efficient and works well in harsh reservoir conditions, in terms of high temperatures at $275^{\circ} \mathrm{F}$ and salinity of arbitrary salt contents. This is a major enhanced discovery as polymer 


\begin{tabular}{|c|c|c|c|c|c|c|c|c|c|c|}
\hline \multirow[b]{2}{*}{$\begin{array}{c}\text { Detail } \\
\text { Table } \\
\text { in } \\
\text { Ref. } 16\end{array}$} & \multirow[b]{2}{*}{$\begin{array}{l}\text { EOR } \\
\text { Method }\end{array}$} & \multicolumn{3}{|c|}{ Oil Properties } & \multicolumn{6}{|c|}{ Reservoir Characteristics } \\
\hline & & $\begin{array}{l}\text { Gravity } \\
\left({ }^{\circ} \mathrm{API}\right)\end{array}$ & $\begin{array}{l}\text { Viscosity } \\
\text { (cp) }\end{array}$ & Composition & $\begin{array}{c}\text { Oil } \\
\text { Saturation } \\
\text { (\% PV) }\end{array}$ & $\begin{array}{c}\text { Formation } \\
\text { Type }\end{array}$ & $\begin{array}{l}\text { Net } \\
\text { Thickness } \\
\text { (ft) }\end{array}$ & $\begin{array}{l}\text { Average } \\
\text { Permeability } \\
\text { (md) }\end{array}$ & $\begin{array}{l}\text { Depth } \\
\text { (ft) }\end{array}$ & $\begin{array}{c}\text { Temperature } \\
\left({ }^{\circ} \mathrm{F}\right)\end{array}$ \\
\hline \multicolumn{11}{|c|}{ Gas Injection Methods (Miscible) } \\
\hline 1 & $\begin{array}{l}\text { Nitrogen and } \\
\text { flue gas }\end{array}$ & $>35>\underline{48}>$ & $<0.4 \backslash \underline{0.2}>$ & $\begin{array}{l}\text { High percent } \\
\text { of } C_{1} \text { to } C_{7}\end{array}$ & $>40>\underline{75}>$ & $\begin{array}{l}\text { Sandstone } \\
\text { or } \\
\text { carbonate }\end{array}$ & $\begin{array}{l}\text { Thin unless } \\
\text { dipping }\end{array}$ & NC & $>6,000$ & NC \\
\hline 2 & Hydrocarbon & $>23>\underline{41}>$ & $\langle 3 \backslash \underline{0.5\rangle}$ & $\begin{array}{l}\text { High percent } \\
\text { of } C_{2} \text { to } C_{7}\end{array}$ & $>30>80>$ & $\begin{array}{l}\text { Sandstone } \\
\text { or } \\
\text { carbonate }\end{array}$ & $\begin{array}{l}\text { Thin unless } \\
\text { dipping }\end{array}$ & NC & $>4,000$ & NC \\
\hline 3 & $\mathrm{CO}_{2}$ & $>22>36>a$ & $<10>\underline{1.5}\rangle$ & $\begin{array}{l}\text { High percent } \\
\text { of } C_{5} \text { to } C_{12}\end{array}$ & $>20>\underline{55}$ & $\begin{array}{l}\text { Sandstone } \\
\text { or } \\
\text { carbonate }\end{array}$ & Wide range & NC & $>2,500^{a}$ & NC \\
\hline $1-3$ & $\begin{array}{l}\text { Immiscible } \\
\text { gases }\end{array}$ & $>12$ & $<600$ & NC & $>35>\underline{70}>$ & NC & $\begin{array}{l}\text { NC if dipping } \\
\text { and/or } \\
\text { good vertical } \\
\text { permeability }\end{array}$ & NC & $>1,800$ & NC \\
\hline \multicolumn{11}{|c|}{ (Enhanced) Waterflooding } \\
\hline 4 & $\begin{array}{l}\text { Micellar/ } \\
\text { Polymer, } \\
\text { ASP, and } \\
\text { Alkaline } \\
\text { Flooding }\end{array}$ & $>20>35$ & $<35 \backslash \underline{13}\rangle$ & $\begin{array}{l}\text { Light, } \\
\text { intermediate, } \\
\text { some organic } \\
\text { acids for } \\
\text { alkaline floods }\end{array}$ & $>35>\underline{53}$ & $\begin{array}{l}\text { Sandstone } \\
\text { preferred }\end{array}$ & NC & $>10>\underline{450}$ & $>9,000 \backslash \underline{3,250}$ & $>200 \backslash \underline{80}$ \\
\hline 5 & $\begin{array}{l}\text { Polymer } \\
\text { Flooding }\end{array}$ & $>15$ & $<150,>10$ & NC & $>50>80$ & $\begin{array}{l}\text { Sandstone } \\
\text { preferred }\end{array}$ & NC & $>10>800>b$ & $<9,000$ & $>200>\underline{140}$ \\
\hline \multicolumn{11}{|c|}{ Thermal/Mechanical } \\
\hline 6 & Combustion & $>10>16 \rightarrow ?$ & $\begin{array}{c}<5,000 \\
\downarrow \\
1,200 \\
\end{array}$ & $\begin{array}{c}\text { Some } \\
\text { asphaltic } \\
\text { components }\end{array}$ & $>50>72$ & $\begin{array}{l}\text { High-porosity } \\
\text { sand/ } \\
\text { sandstone }\end{array}$ & $>10$ & $>50^{c}$ & $<11,500 \backslash \underline{3,500}$ & $>100>135$ \\
\hline 7 & Steam & $>8$ to $\underline{13.5} \rightarrow ?$ & $\begin{array}{c}<200,000 \\
\downarrow \\
4,700 \\
\end{array}$ & NC & $>40>\underline{66}$ & $\begin{array}{l}\text { High-porosity } \\
\text { sand/ } \\
\text { sandstone }\end{array}$ & $>20$ & $>200>\underline{2,540} \not d$ & $<4,500 \backslash \underline{1,500}$ & NC \\
\hline- & Surface mining & 7 to 11 & $\begin{array}{l}\text { Zero } \\
\text { cold flow }\end{array}$ & NC & $\begin{array}{l}>8 \text { wt } \% \\
\text { sand }\end{array}$ & $\begin{array}{l}\text { Mineable } \\
\text { tar sand }\end{array}$ & $>10^{e}$ & NC & $\begin{array}{l}\quad>3: 1 \\
\text { overburden to } \\
\text { sand ratio }\end{array}$ & NC \\
\hline \multicolumn{11}{|c|}{$\begin{array}{l}\text { NC }=\text { not critical. } \\
\text { Underlined values represent the approximate mean or average for current field projects. } \\
\text { aSee Table } 3 \text { of Ref. } 16 \text {. } \\
\text { b }>3 \text { md from some carbonate reservoirs if the intent is to sweep only the fracture system. } \\
\text { Transmissibility }>20 \text { md-ft/cp } \\
\text { dTransmissibility }>50 \text { md-ft/cp } \\
\text { eSee depth. }\end{array}$} \\
\hline
\end{tabular}

Fig. 4 Summary of screening criteria for EOR methods Taber et al. (1997)and Sheng (2015

projects before did not pass the stage of a pilot project or a single-block application based on restrictions of the high salt content of 120,00 to 190,000 ppm, water harshness and iron II content. Absorbance of polymer onto soil types proves to have a profitable approach as mentioned by Ustick and Hillhouse (1967) in the Huntington Beach field, Orange County, California. A comparison of waterflood and polymer flood was used on the same field, and polymer flooding results were outstandingly better than waterflooding results.

It has been shown in previous studies that polymer flooding and polymer injection have proven to be one of the most important chemical EOR methods in reservoirs and that the degree of success depends heavily on the soil type present in the formations and improving the aspects of the displacement efficiency and sweep efficiency methods on viscosity and adsorption characteristics. Research in this area in Trinidad and Tobago is limited, and although preliminary simulation data were presented on the EOR 44 test well, input adsorption and viscosity data were lacking. This study will incorporate adsorption and viscosity data obtained using a range of xanthan gum and aquagel polymer gel concentrations on different soil types within numerical simulation models to determine the technical feasibility of implementing a polymer flood on the EOR 44 well.

\section{Methodology}

\section{Raw materials}

Gravel-packed sand used for this experiment was obtained in the Petroleum Laboratory at the University of Trinidad and Tobago which was obtained from a reservoir in Trinidad. The clays were mined from the Longdenville and Valencia natural deposits in central and northeastern Trinidad, respectively, and obtained through the Department of Physics, University of the West Indies, St. Augustine, Trinidad. To compensate for the variability in clay quality with depth and lateral location as mining progresses, an appropriate sampling technique similar to that used by Knight (1999) was employed. The samples were crushed and ground and sieved through a $100-\mu \mathrm{m}$ sieve size mesh. Xanthan gum polymer and aquagel polymer samples were provided by the team at Baroid Trinidad Services Limited. 


\section{Clay sample characterization}

The chemical composition of the naturally occurring Valencia and Longdenville clays was determined using approximately $15 \mathrm{~g}$ of previously dried sample and pressed using a Graseby Press for $20 \mathrm{~s}$ at 20 tons load/force. The sample disk was mounted in an ARL 8620 X-Ray Fluorescence (XRF) Spectrometer interfaced with the WinXRF Software and analyzed.

\section{Adsorption studies}

Working polymer solutions of concentrations of aquagel and xanthan gum polymers were made at concentrations $250 \mathrm{ppm}$, 500 ppm, 1000 ppm, 2000 ppm, 4000 ppm, 6000 ppm, $8000 \mathrm{ppm}, 10,000 \mathrm{ppm}$ and $20,000 \mathrm{ppm}$. This working range encompassed typical polymer dosages utilized in industry. The corresponding absorbance readings were measured in the HACHDR 5000 UV-Vis spectrophotometer machine at the $\lambda_{\text {max }}$ wavelength values of $280 \mathrm{~nm}$ and $340 \mathrm{~nm}$ for aquagel and xanthan gum polymers, respectively. The data were then utilized for plotting a calibration graphs for the aquagel and xanthan gum polymers which will be used for the quantization of the absorbed polymer in subsequent experiments.

The three soil types consisting of Valencia clay, Longdenville clay and gravel pack sand were used as were preheated before use at $150{ }^{\circ} \mathrm{C}$ for $3 \mathrm{~h}$. Each of the three soil support samples $(1 \mathrm{~g})$ was mixed with solutions of the two polymers at the various concentrations, and these samples were allowed to equilibrate for $24 \mathrm{~h}$ at ambient temperature naturally before analysis. Subsequent to equilibration, the solutions were filtered and the concentrations of the unabsorbed polymer in the filtrate were quantified using the calibration curve generated.

\section{Viscosity studies}

The viscosities of $2000 \mathrm{ppm}, 1000 \mathrm{ppm}$ and $250 \mathrm{ppm}$ concentrations of xanthan gum and aquagel polymer solutions were analyzed using an OFITE- 8 speed rotational viscometer as described in the user manual Testing Equipment Inc (2015). Measurements of viscosities were recorded for shear rates at $600 \mathrm{rpm}, 300 \mathrm{rpm}, 200 \mathrm{rpm}, 100 \mathrm{rpm}, 6 \mathrm{rpm}$ and gel (3 rpm). Values of shear stress, shear rate and viscosity were calculated using the following relationships (Testing Equipment Inc (2015)):

Shear stress, $\mathrm{lbf} / 100 \mathrm{ft}^{2}=1.067 \times \theta$

Shear rate, $\mathrm{s}^{-1}=\mathrm{RPM} \times 1.703$

Viscosity, $\mathrm{Pa} \mathrm{s}^{-1}=\frac{\text { Shear stress }}{\text { Shear rate }}$.

\section{Simulation studies}

The field data presented in Table 1 and the results of the adsorption and viscosity studies were used to design the simulation models using Computer Modeling Group (CMG) Limited software. Properties were added into the design which would allow for maintaining the accurate model of the reservoir. The dimensions for layers were $100 * 60 * 5$, respectively. The bubble point, fracture pressure, reservoir temperature, maximum pressure and oil density were 1343.13 psi, 1604 psi, $120^{\circ} \mathrm{F}, 5000 \mathrm{psi}$ and $29^{\circ} \mathrm{API}$, respectively. The water and oil saturations were 0.55 and 0.45 , respectively. These values are key inputs in designing the EOR 44 well. After simulations, the .fhf file obtained is then run through Computer Modeling Intelligent Optimization and Analysis Tool (CMOST-Al). As such, the following results are obtained: the polymer mole fraction, water mole fraction, polymer slug period, water slug period and the optimized oil recovery.

\section{Results and discussion}

\section{Characterization of clays}

The results obtained from the X-ray fluorescence (XRF) study shown in Table 2 found that the aluminum oxide content (usually associated with kaolinite) was $10.9 \%$ and $15.9 \%$ for Longdenville and Valencia clays, respectively. Although the silicon oxide and calcium oxide content was similar for both materials $(\approx 6 \%)$, the iron oxide content of the Valencia clay (1.91\%) was significantly lower than that in the Longdenville clay $(6.77 \%)$. These findings were consistent with the previous work done by Knight (1999) on the chemical and mineralogical composition of naturally occurring Trinidad clays. His study showed that the Valencia and Longdenville clays were both kaolinitic and contained quartz, mica, potash feldspar and calcite; however, the Valencia clay had a higher quartz and mica content but lower iron content than the Longdenville clay.

\section{Adsorption studies}

The standard solutions of various concentrations of the two polymer flooding compounds were prepared, and the

Table 2 X-ray fluorescence analysis of Valencia and Longdenville clays

\begin{tabular}{lllll}
\hline & $\mathrm{SiO}_{2}(\%)$ & $\mathrm{Al}_{2} \mathrm{O}_{3}(\%)$ & $\mathrm{Fe}_{2} \mathrm{O}_{3}(\%)$ & $\mathrm{CaO}(\%)$ \\
\hline Longdenville clay & 68.99 & 10.85 & 6.77 & 6.32 \\
Valencia clay & 67.86 & 15.85 & 1.91 & 6.29 \\
\hline
\end{tabular}


resulting calibration curves are plotted and shown in Figs. 5 and 6 for aquagel and xanthan gum, respectively.

For both materials, quantitation of the unabsorbed polymers was conducted using the linear part of the respective curves consistent with the standard laboratory practice.
A comparison of the adsorption capacities of the various soil materials with the xanthan gum and aquagel polymers with increasing polymer concentrations is shown in Figs. 7 and 8 , respectively.
Fig. 5 Aquagel polymer calibration curve at a $\lambda_{\max } 280 \mathrm{~nm}$

Fig. 6 Xanthan gum polymer calibration curve at $\lambda_{\max }$ $340 \mathrm{~nm}$

Fig. 7 Xanthan gum polymer adsorption on sand, Valencia clay and Longdenville clay
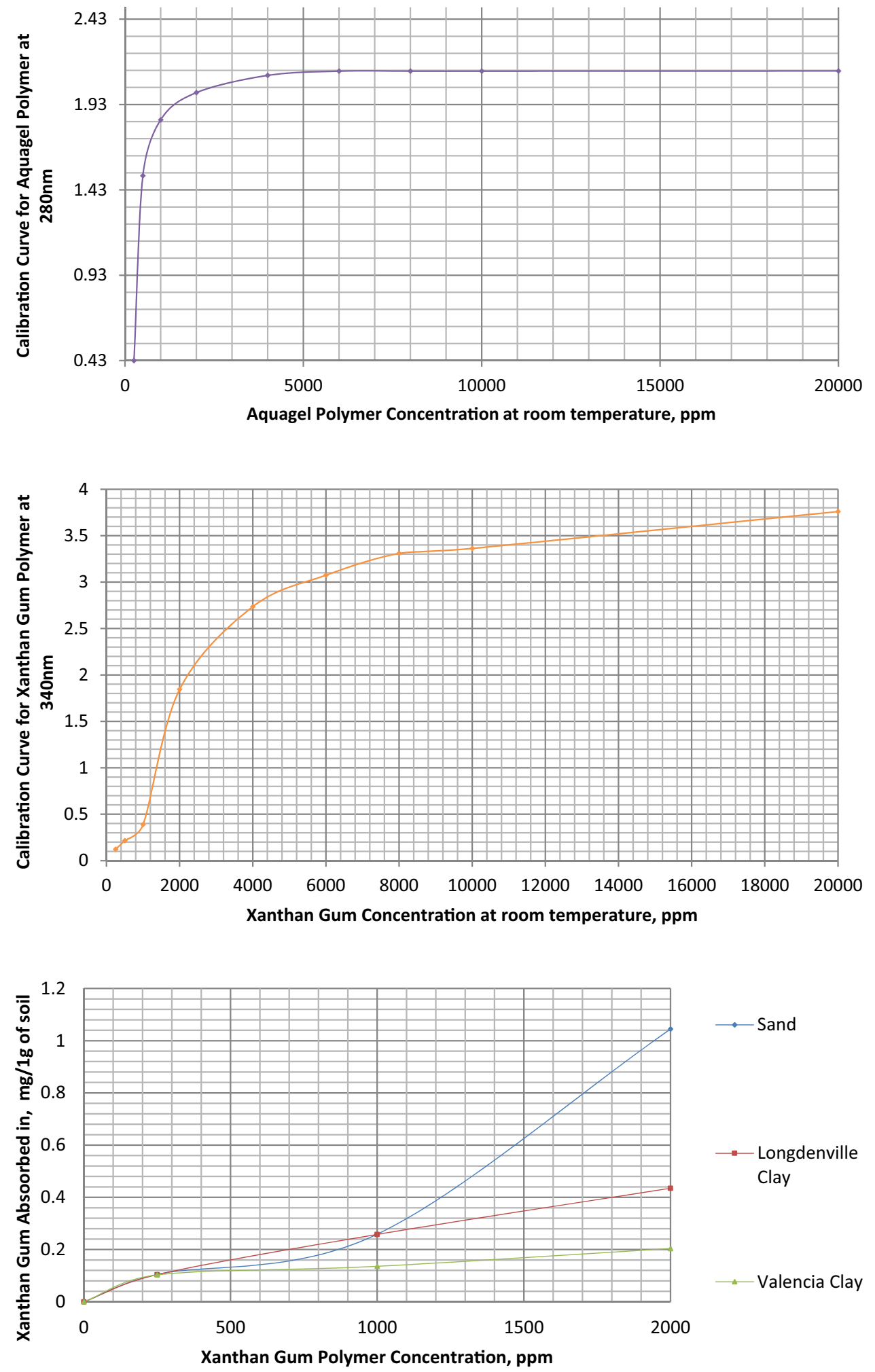

Xanthan Gum Polymer Concentration, ppm 
Fig. 8 Aquagel polymer adsorption on sand, Valencia clay and Longdenville clay

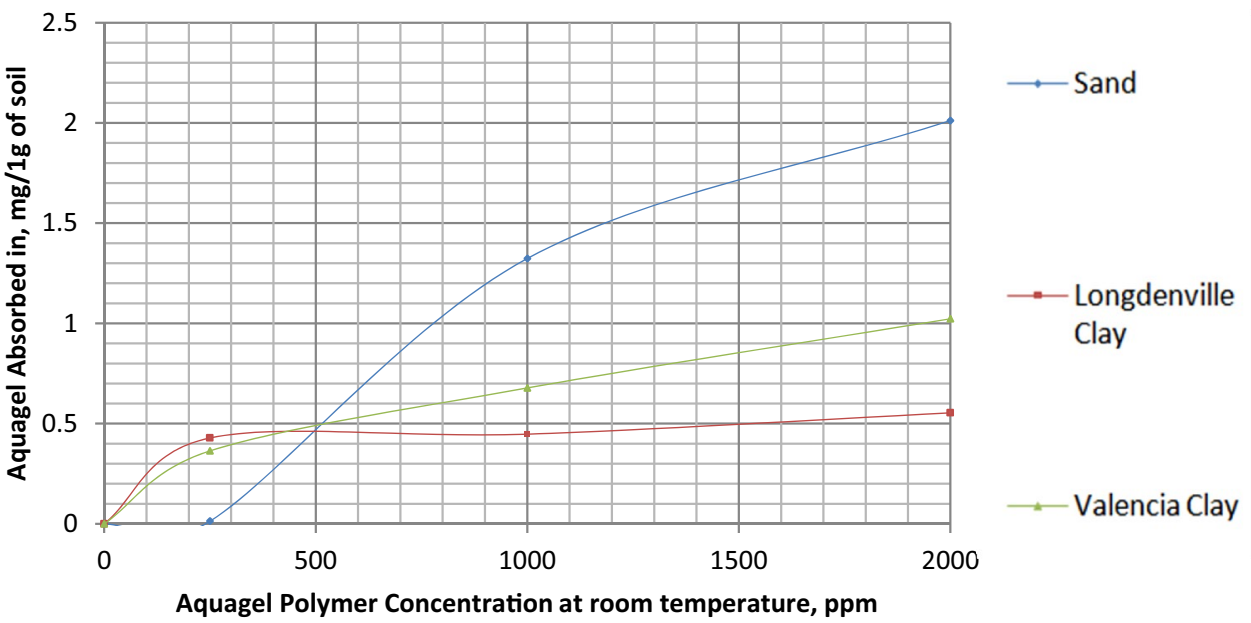

As shown in Fig. 7, xanthan gum exhibited the lowest adsorption capacity for Valencia clay over the entire concentration range. Sand had the highest adsorption capacity for xanthan gum at concentrations above $1000 \mathrm{ppm}$, while the Longdenville clay was the highest absorbent below $1000 \mathrm{ppm}$. At xanthan gum concentrations below $250 \mathrm{ppm}$, all three soil-type absorbent materials exhibited similar adsorption capacities. As far as the aquagel polymer is concerned and as shown in Fig. 8, it was evident that aquagel was significantly more absorbed on the soil types compared to xanthan gum. In fact at the $2000 \mathrm{ppm}$ concentration level, almost twice the amount of aquagel was absorbed by the soil types compared to xanthan gum. Similar to the trends obtained for xanthan gum, the lowest adsorption capacity was observed for Valencia clay at concentration levels above 500 ppm; however, the clay had the highest adsorption capacity below this level. Sand had the highest adsorption capacity for aquagel at concentrations above 500 ppm, while the Longdenville clay was the lowest absorbent above $500 \mathrm{ppm}$. Generally, all three soil types had a similar adsorption capacity for xanthan gum at a concentration level of $250 \mathrm{ppm}$ and for aquagel at a concentration level of $500 \mathrm{ppm}$.

The results offered conclusive evidence demonstrating the importance that the pore structure characteristics including morphology and porosity of natural materials (rocks, soils, etc.) that may be present in oil wells for example can play in determining the physical properties and behavior of the material, how they interact with stored fluid in them in terms of adsorption characteristics, flow, precipitation and reactions as previously suggested by Anovitz and Cole (2015). The understanding of these porous structures is critical to properly comprehend, model and predict the evolution of these geological features especially as it relates to processes such as $\mathrm{CO}_{2}$ sequestration or in this case, the EOR polymer flooding strategy of EOR 44. Evidence of the influence of pore structure characteristics on the adsorption characteristics of surfaces was demonstrated by the results of adsorption studies conducted by Saleh (2015a, b, 2016) as studies investigating the adsorption characteristics of various substrates such as silica combined with $2 \%$ multiwall carbon nanotubes $\left(\mathrm{SiO}_{2}-\mathrm{CNT}\right)$, nanocomposites of silica incorporated with carbon nanotubes (silica/CNT) and activated carbon (silica/AC) and adsorption of mercury ions as well as nanocomposite of carbon nanotubes/silica nanoparticles and adsorption of $\mathrm{Pb}(\mathrm{II})$ produced varying results in terms of adsorption capacity and efficiency.

The results of this study offer supporting evidence to previous research conducted by Alvarez et al. (2017), who demonstrated that surfactant adsorption depends on the type and composition of the soil as well as the type of additive being used. XRF studies discussed earlier highlighted the compositional differences of both clays where the Valencia clay had a higher quartz and mica content but lower iron content than the Longdenville clay. The results of this adsorption study will be factored in the subsequent simulation exercises.

\section{Viscosity studies}

As discussed earlier, viscosity data are important in the prediction of the suitability of the use of polymer flooding in EOR for a particular well. As outlined by Glatz (2013) and Olajire (2014) as it applies to polymer flooding, the mobility ratio $(M)$ is defined as the ratio of mobility $(\lambda)$ of the displacing fluid (water) to the mobility of the displaced fluid (oil), where mobility is permeability $(\kappa)$ divided by viscosity $(\mu)$. The mobility ratio is dependent on the volumetric sweep efficiency. If $M$ is greater than 1 , the process will be unfavorable since it will result in instability of the displacement process referred to as "viscous fingering." If there is a large viscosity difference between the displacing (water, lower viscosity) and displaced (oil, higher viscosity) fluid, $M$ will become larger than one and, thus, poor recovery will be reached, which leads to a significant reduction in production 
at well site. On the other hand, if $M$ decreases below one, using viscous fluid (polymer) to increase the viscosity of displacing fluid is feasible and it promotes the displacing fluid in a stable, uniform manner and reducing the possibility of fingering, thus increasing the efficiency of oil recovery.

Figure 9 depicts the viscosities of various xanthan gum and aquagel polymer solutions of varied concentrations at $3 \mathrm{rpm}$. The trends observed were typical of those obtained at other shear rates. Generally, aquagel polymer solutions exhibited lower viscosities than the xanthan gum polymer solutions. At a concentration level of 2000 ppm, for instance, xanthan gum polymer was approximately twice as viscous as the aquagel polymer solution.

\section{Simulation results and analysis}

Simulations were conducted by using the CMG software. The software contains a variety of aspects to help generate the best model of the reservoir under investigation. The first stage was the geo-model generation. Here, the structural map of EOR 44 field was digitized. The IMEX component of the software then allowed for grids to be created. Stage two was using the field production data for the oil, water and gas rates. These data were obtained by digitization so that overall .fhf files were created. Stage three was base model generation which involved adding in the EOR 44 reservoir properties, fluid properties and initial conditions. Also, the setting of wells and recurrent and creation of groups were done, In addition to which this stage allowed for the addition of .prd files so as creation of groups is achieved. The net to gross ratio was also inputted at this stage. Stage four was the step of converting the IMEX model to STARS model.
In stage five, components of carbon dioxide were added. Stage six was carbon dioxide being set as the injected fluid. Isothermal was ensured to be ON. Stage seven was important because it was model validation by history matching. Finally, after the model of the reservoir was created and built exactly as what is required EOR model selection can be done. Typically, this is when waterflooding and polymer flooding can be tested on the model using simulations.

The input data included reservoir data from EOR 44, and the input information was obtained from the results of the adsorption and viscosity studies. The results of the simulation exercise as shown in Table 2 illustrate the optimized cases for xanthan gum and aquagel polymer flood for EOR 44. The parameters shown are polymer mole fraction, water mole fraction, polymer slug period, water slug period and optimized oil recovery. Polymer mole fraction refers to how much polymer to water is to be incorporated into the flood. Water mole fraction refers to how much water to polymer is to be incorporated into the flood. Polymer slug is a term which refers to the polymer and water mixture. The polymer slug period is when the polymer mixture is injected into the reservoir. Similarly, water slug period is when water is injected into the reservoir. Optimized oil recovery is how much of the hydrocarbons were retrieved after EOR methods were utilized.

As we examine in Table 3, we see xanthan gum polymer flood uses a lower polymer mole fraction of $1.4521824 \mathrm{e}-6$ in comparison with the aquagel polymer flood of 5.801921e-7. This indicates that when aquagel polymer mixed into water the adsorption rate is 0.002 times approximately greater in the water than when xanthan gum polymer is mixed into water, in which less adsorption rate is absorbed. Also, we
Fig. 9 Viscosity (cp) of xanthan gum and aquagel solutions at various concentration levels at a shear rate of $3 \mathrm{rpm}$

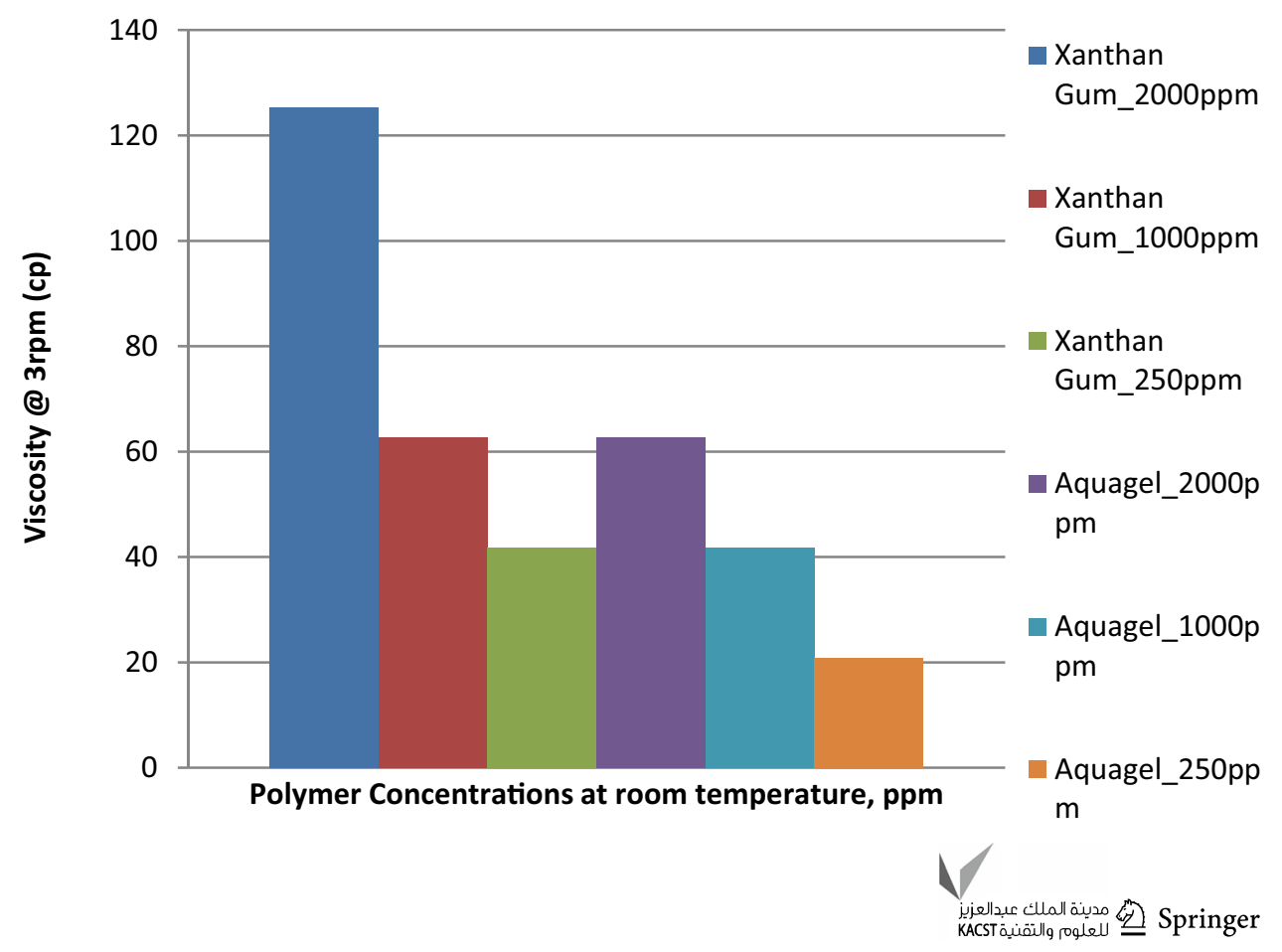


Table 3 Flood optimization data for polymer flooding

\begin{tabular}{lll}
\hline Parameter & $\begin{array}{l}\text { Xanthan gum flood } \\
\text { optimization data }\end{array}$ & $\begin{array}{l}\text { Aquagel flood } \\
\text { optimization } \\
\text { data }\end{array}$ \\
\hline Polymer mole fraction & $1.4521824 \mathrm{e}-6$ & $5.801921 \mathrm{e}-7$ \\
Water mole fraction & 0.99999855 & 0.99999942 \\
Polymer slug period, days & 36.5 & 73 \\
Water slug period, days & $292,613.5$ & 292,577 \\
Optimized oil recovery, STB & 8.37 & 8.43 \\
\hline
\end{tabular}

see that the water mole fraction for xanthan gum polymer flood is again lowered by $8.7 \mathrm{e}-7$ in comparison with aquagel polymer flood. This indicates that the water ratio is lower for mixing xanthan gum polymer to aquagel polymer. The polymer slug period for xanthan gum polymer flood is 36.5 days but higher for aquagel polymer flood of 73 days. This indicates that it takes approximately 37 days for the maximum amount of oil using xanthan gum polymer flood to be recovered and similarly 73 days is the lengthy time frame to inject the aquagel polymer flood so as to obtain the maximum amount of oil in the reservoir. However, it is opposite when a comparison is made for the water slug period for both polymer flooding cases, respectively. It illustrates that xanthan gum polymer flood needs an additional 365 days for a water slug period compared to aquagel polymer flood which needs only 292,577 days. Overall, aquagel polymer flood seems to give higher oil recovery by 0.06 STB than the xanthan gum polymer flood giving 8.37 STB.

A careful look tells that if both floods are injected at the same conditions into the reservoir it is astonishing to see that xanthan gum flood had a lower polymer mole fraction, water mole fraction and polymer slug period with a higher water slug period which gives an overall recover of 8.37STB. If comparison is made with the aquagel flood, it is the opposite response which was shown with the xanthan gum flood. More precisely, the aquagel flood had a higher polymer mole fraction, water mole fraction and polymer slug period with a lower water slug period which gave an overall recovery of $8.43 \mathrm{STB}$. The better choice of both the polymer floods would be selecting the aquagel polymer flood based on higher oil recovery. This means that even though we see that there is a slight chance of obtaining only a mere amount of 0.06 STB more oil with aquagel polymer flood it is not recommended to utilize a xanthan gum polymer flood. The results showed that the aquagel polymer flood would be more suitable to use compared to xanthan gum polymer flood both in terms of oil recovery.

Summarizing the above mention in a nut shell, all parameters in cases of xanthan gum and aquagel floods showed that the optimized oil recovery was a \pm 0.1 difference in value in comparison to each other. Xanthan gum polymer
Table 4 Oil recovered with primary recovery, $\mathrm{CO}_{2}$ injection, waterflood and polymer floods

\begin{tabular}{lc}
\hline Floods (\%) & $\begin{array}{l}\text { Oil recov- } \\
\text { ered (STB) }\end{array}$ \\
\hline Primary & 71.9 \\
$\mathrm{CO}_{2}$ injection & 3.42 \\
Water & 8.28 \\
Xanthan gum polymer & 8.37 \\
Aquagel polymer & 8.43 \\
\hline
\end{tabular}

flood showed a lower recovery in relation to aquagel polymer flooding. Ideally, it is wise to use the aquagel polymer flood rather than a xanthan gum polymer flood.

Table 4 refers to methods used to obtain oil from the same well under investigation. We see that there were five methods: $\mathrm{CO}_{2}$ injection, waterflooding, xanthan gum, polymer flood and aquagel polymer flood. Primary is the normal pressures of the reservoir which pushes the oil out naturally and resulted in 71.9 STB of oil. A resulting pressure results in the need to pump the remaining oil out into the surface. $\mathrm{CO}_{2}$ injection was then incorporated into the well, and the gas allowed for 3.42 STB of oil out into the surface. Since the evidence points to the existence of a large amount of oil reserves, the three EOR methods were investigated. Waterflooding is the injection of water into the reservoir which allowed for 8.23 STB of oil to be obtained. There were two polymer floods examined of which only aquagel polymer flood showed a higher oil recovery of 8.43 STB in comparison with the xanthan gum polymer flood of 8.37 STB. This indicates that between both polymer floods aquagel gives a higher oil recovery than the xanthan gum polymer flood. Additionally, if comparison of waterflooding method is used rather than a polymer flood, the oil recovery will be lower. This shows that polymer flooding has a greater impact on hydrocarbon recovery than a waterflood overall.

\section{Conclusion}

Due to their different properties, the performance of xanthan gum and aquagel polymers is dependent on working conditions. The results of the adsorption behavior of xanthan gum and aquagel polymer flooding chemicals on soil types of different concentrations demonstrated that retention of polymer flooding agents is affected by rock composition and type and polymer concentration. Additionally, viscosity studies conducted demonstrated that the polymer type and concentration level influenced the mobility ratio as evidenced its effect on the rheological and flow properties of the flooding agents. Polymer adsorption and viscosity data obtained in the laboratory were incorporated into numerical simulation 
models to determine the technical feasibility of implementing a polymer flood on the EOR 44 well. The results showed that overall, aquagel polymer flood resulted in a higher oil recovery compared to the xanthan gum polymer flood. Aquagel polymer flood is typically the better EOR method in this case. Additionally, both cases of polymer flooding resulted in higher levels of oil recovery compared to $\mathrm{CO}_{2}$ injection and waterflooding and therefore polymer flooding will have greater impact on the EOR 44 well oil recovery.

Open Access This article is licensed under a Creative Commons Attribution 4.0 International License, which permits use, sharing, adaptation, distribution and reproduction in any medium or format, as long as you give appropriate credit to the original author(s) and the source, provide a link to the Creative Commons licence, and indicate if changes were made. The images or other third party material in this article are included in the article's Creative Commons licence, unless indicated otherwise in a credit line to the material. If material is not included in the article's Creative Commons licence and your intended use is not permitted by statutory regulation or exceeds the permitted use, you will need to obtain permission directly from the copyright holder. To view a copy of this licence, visit http://creativecommons.org/licenses/by/4.0/.

\section{References}

Alvarez JO, Saputra IWR, Schechter DS (2017) The impact of surfactant imbibition and absorption for improving oil recovery in the Wolfcamp and Eagle Ford Reservoirs. https://www-onepetroorg.research.library.u.tt/download/conference-paper/SPE-18717 6-MS?id=conference-paper\%2FSPE-187176-MS

Anovitz LM, Cole DR (2015) Characterization and analysis of porosity and pore structures. Rev Mineral Geochem 80:61-164

Firozjaii AM, Saghafi HR (2019) Review on chemical enhanced oil recovery using polymer flooding: fundamentals, experimental and numerical simulation. Petroleum. https://doi.org/10.1016/j.petlm .2019 .09 .003

Fondevila Sancet G, Goldman M, Buciak JM, Varela O, Fascio M, Manzano V, Luong M (2018) SPE-190408-MS molecular structure characterization and interaction of a polymer blend of xanthan gum-polyacrylamide to improve mobility-control on a mature polymer Flood. Retrieved from https://www-onepetroorg.research.library.u.tt/download/conference-paper/SPE-19040 8-MS?id=conference-paper\%2FSPE-190408-MS

Glatz G (2013) A primer on enhanced oil recovery. Physics 240, Stanford University, Fall 2013

Grain size (n.d.) Retrieved from http://weppi.gtk.fi/publ/foregsatlas/ text/Grainsize.pdf

Knight JC (1999) Influence of volcanic ash as flux on ceramic properties of low plasticity clay and high plasticity clay of Trinidad. $\mathrm{Br}$ Ceram Trans 98(1):24-28

Leonhardt B, Ernst B, Reimann S, Steigerwald A, Holding GmbH W (2014) SPE-169032-MS field testing the polysaccharide schizophyllan: results of the first year. Retrieved from https://wwwonepetro-org.research.library.u.tt/download/conference-paper/ SPE-169032-MS?id=conference-paper\%2FSPE-169032-MS

Ministry of Energy and Energy Industries (2019) Retrieved from historical facts on the petroleum industry of Trinidad and Tobago. http://www.energy.gov.tt/historical-facts-petroleum/
Mohammad-Singh LJ, Singhal AK (2004) Lessons from Trinidad's $\mathrm{CO}_{2}$ immiscible pilot projects 1973-2003. Retrieved from https ://www-onepetro-org.research.library.u.tt/download/conference -paper/SPE-89364-MS?id=conference-paper\%2FSPE-89364-MS

Olajire A (2014) Review of ASP EOR (alkaline surfactant polymer enhanced oil recovery) technology in the petroleum industry: prospects and challenges. Energy 77:963

Saleh TA (2015a) Isotherm, kinetic, and thermodynamic studies on $\mathrm{Hg}$ (II) adsorption from aqueous solution by silica-multiwall carbon nanotubes. Environ Sci Pollut Res Int 22:16721-16731. https://doi.org/10.1007/s11356-015-4866-z

Saleh TA (2015b) Mercury sorption by silica/carbon nanotubes and silica/activated carbon: a comparison study. J Water Supply Res Technol AQUA 64(8):892-903. https://doi.org/10.2166/ aqua. 2015.050

Saleh TA (2016) Nanocomposite of carbon nanotubes/silica nanoparticles and their use for adsorption of $\mathrm{Pb}$ (II): from surface properties to sorption mechanism. Desalin Water Treat 57(23):10730-10744. https://doi.org/10.1080/19443994.2015.1036784

Sheng JJ (2015) Status of polymer-flooding technology. Retrieved from https://www-onepetro-org.research.library.u.tt/download/journalpaper/SPE-174541-PA?id=journal-paper\%2FSPE-174541-PA

Sinanan B, Evans D, Budri M (2016) SPE 180853-MS: conceptualizing an improved oil recovery master plan for Trinidad \& Tobago. SPE J. https://doi.org/10.2118/180853-ms

Speight JG (2013) Nonthermal recovery of heavy oil. In heavy oil production processes, pp 63-92. https://doi.org/10.1016/b978-012-401720-7.00004-6

Taber JJ, Martin FD, Seright RS (1997) EOR screening criteria revisited part 1: introduction to screening criteria and enhanced recovery field projects. In SPE reservoir engineering. Retrieved from https://www-onepetro-org.research.library.u.tt/download/journ al-paper/SPE-35385-PA?id=journal-paper\%2FSPE-35385-PA

Testing Equipment Inc O (2015) Model 800 viscometer \#130-10-C-with carrying case and power supply \#130-10-L-with retractable legs (for kits) instruction manual. http://www.ofite.com/publications/ instructions/119-130-10-instructions/file

Trinidad and Tobago Economy (2019) Retrieved from 2019 CIA World Fact book and other sources: https://theodora.com/wfbcurrent/ trinidad_and_tobago/trinidad_and_tobago_economy.html

Ustick RE, Hillhouse JD (1967) Comparison of polymer flooding and waterflooding at Huntington Beach, California. Retrieved from https://www-onepetro-org.research.library.u.tt/journal-paper/SPE1734-PA ?sort $=\&$ start $=0 \& \mathrm{q}=$ Comparision + of + Polymer + Floodi ng+and+Waterflooding +at+Huntington+Beach $\% 2 \mathrm{C}+$ California $\&$ from_year $=\&$ peer_reviewed $=\&$ published_between $=\&$ fromSe archResults $=$ true \& to_year $=\&$ rows $=25 \#$

Van der Hoek J, Botermans CW, Zitha PLJ (2001) Full blocking mechanism of polymer gels for water control, SPE 68982. In: Proceedings of society of petroleum engineers European formation damage conference, The Hague, The Netherlands, 21-22 May 2001

Willhite GP (1986) Waterflooding (Spe textbook series) (1986, Society of Petroleum)

Publisher's Note Springer Nature remains neutral with regard to jurisdictional claims in published maps and institutional affiliations. 